\title{
DRD4 Gene Polymorphisms as a Risk Factor for Children with Attention Deficit Hyperactivity Disorder in Iranian Population
}

\author{
Seyed Mahmoud Tabatabaei, ${ }^{1,2}$ Shahrokh Amiri, ${ }^{2}$ Sara Faghfouri, ${ }^{2}$ \\ Seyed Gholamreza Noorazar, ${ }^{2}$ Shahin AbdollahiFakhim, ${ }^{3}$ and Ali Fakhari ${ }^{2}$ \\ ${ }^{1}$ Department of Physiology, Tabriz Branch, Islamic Azad University, Tabriz, Iran \\ ${ }^{2}$ Research Center of Psychiatry and Behavioral Sciences, Tabriz University of Medical Sciences, Tabriz, Iran \\ ${ }^{3}$ Department of Otolaryngology, Head and Neck Surgery, Tabriz University of Medical Sciences, Tabriz, Iran \\ Correspondence should be addressed to Shahrokh Amiri; amirish@tbzmed.ac.ir
}

Received 27 February 2017; Revised 13 April 2017; Accepted 23 April 2017; Published 24 May 2017

Academic Editor: Pieter J. Hoekstra

Copyright (C) 2017 Seyed Mahmoud Tabatabaei et al. This is an open access article distributed under the Creative Commons Attribution License, which permits unrestricted use, distribution, and reproduction in any medium, provided the original work is properly cited.

\begin{abstract}
Background and Objective. Dopamine dysfunction is known to be associated with attention deficit hyperactivity disorder (ADHD). Dopamine D4 receptor gene (DRD4) is one of the important genes in this pathway. This study intended to investigate the variable number of tandem repeats (VNTR) in exon 3 of the DRD4 gene in Iranian children and adolescents. Materials and Methods. In this study, 130 children with ADHD, aged 6-14 years, and 130 healthy children, within the same age range, were enrolled. All children were selected from northwest of Iran which have Caucasian ethnic background and are of a Turkic ethnic group. VNTR polymorphisms of the DRD4 gene were evaluated by PCR using exon 3-specific primers followed by agarose gel electrophoresis. Findings. The Hardy-Weinberg principle and Chi-square test showed a significant difference in 4-repetition (4R) alleles between the ADHD (76.2\%) and control (53.8\%) groups $\left(p=0.004 ; X^{2}=17.39 ; \mathrm{df}=5\right)$. The least percentage of repetition alleles in both groups was 2R. Conclusion. There is a significant correlation between the 4R alleles of DRD4 and ADHD in the northwest of Iran.
\end{abstract}

\section{Introduction}

ADHD is a common childhood psychiatric disorder that is associated with the symptoms of sustained hyperactivity, impulsiveness, and inattentiveness. The worldwide prevalence is $4-8 \%$ in school-aged children, which may persist during adolescence and adulthood in $50-80 \%$ of cases [1]. A comparable prevalence is reported from Iranian population and the rate is estimated to be $9.7 \%$ in children living in Tabriz city [2].

$\mathrm{ADHD}$ is a heterogeneous neurobehavioral disorder with multifactorial etiology, leading to neural pathway alternations [3]. The phenotype is quite wide and includes impaired social functioning and skill acquisition and decreased cognitive abilities. These increase the burden of undiagnosed and untreated ADHD with a significant impact on the career, life, and academic achievements $[4,5]$.
Diagnosing ADHD is currently based on clinical similarities, like other psychiatric conditions. The diverse phenotype results in diagnostic challenges $[6,7]$ that should be addressed by improvement of diagnostic methods. Toward this approach, pharmacological studies, animal models, and brain imaging all show the involvement of catecholamine pathways including neurotransmitters and related genes [8]. Dopamine and norepinephrine are involved in neurological functions, as well as attentiveness and awareness [8]. On the other hand, dopamine pathways are involved in motor control and in controlling the release of various hormones. These pathways and cell groups form a dopamine system which is neuromodulatory. The motor functions of dopamine are linked to a separate pathway, with cell bodies in the substantia nigra that manufacture and release dopamine into the dorsal striatum. DRD4 gene that is expressed in several brain areas has also been investigated in relation to 
ADHD [9, 10]. Linkage mapping shows the locus of this receptor gene on chromosome 11p15.5 [11]. This gene has several polymorphisms in its nucleotide sequence. The 48base pair variable number tandem repeat (VNTR) in exon III of DRD4 polymorphism is the most studied polymorphism in association with ADHD. Biological molecular studies show that this region couples to G-protein, modulating cAMP production [12].

The length of exon III varies between 2 and 11 repeats of a similar 48-bp VNTR, presented by D4.2 to D4.11 [13]. Typically, these repetition alleles have two categories: short repeat length allele (2-4 repetitions) and long repeat length allele (5-8 repetitions) [14]. Meta-analysis shows that variants 2, 4, and 7 are far more common [15].

There are evidences supporting significant relationship between 7-repeat alleles of DRD4 exon III polymorphism and ADHD [16-19]. On the other hand, another group of studies have reported a weak correlation between DRD4 and ADHD $[20,21]$. However, it is not well known if these negative results are due to the difference between groups and populations with different race, genetics, and heterogeneity, weakness in performing and interpreting statistical tests, or a real difference between different societies. As a result, this study aimed to investigate the relationship of DRD4 polymorphism with ADHD in Iranian population.

\section{Materials and Methods}

The present study was conducted in a child and adolescent psychiatry clinic of Tabriz University of Medical Sciences. The procedure was approved by the regional ethical committee and written informed consent was obtained from parents of participated children and adolescents.

\section{Inclusion and Exclusion Criteria}

The inclusion criteria were children and adolescent, aged 6-18 years, diagnosed with $\mathrm{ADHD}$, based on clinical interviews conducted by a children and adolescent psychiatrist.

The exclusion criteria were concurrent psychiatric disorder, epilepsy, a serious medical condition or history of severe trauma, and any degree of intellectual disability. ADHD cases with comorbid ODD and/or CD were excluded.

\section{Participants}

This study was conducted in northwest of Iran. The populations living in these areas have Caucasian ethnic background and are of a Turkic ethnic group. Children diagnosed with ADHD $(n=130)$ in specialized psychiatric clinic were included by a child and adolescent psychiatrist. In this study, ADHD diagnosis was carried out through a semistructured diagnostic interview based on DSM-IV-IR criteria.

A group of children $(n=130)$, who were introduced for adenotonsillectomy procedure, within the same age range, were taken as the controls. These children were diagnosed to have no psychiatric condition by the same diagnostic procedure as children with ADHD. An informed written consent was obtained from all parents.
TABLE 1: Temperature plan used for proliferation of DRD4 exon III.

\begin{tabular}{lccc}
\hline Cycle number & Stage & Temperature & Duration \\
\hline One & First denaturation & $95^{\circ} \mathrm{C}$ & $5 \mathrm{~min}$ \\
\hline \multirow{3}{*}{ Thirty-five } & Denaturation & $93^{\circ} \mathrm{C}$ & $20 \mathrm{sec}$ \\
& Annealing & $55^{\circ} \mathrm{C}$ & $20 \mathrm{sec}$ \\
& Extension & $72^{\circ} \mathrm{C}$ & $30 \mathrm{sec}$ \\
\hline One & Final extension & $72^{\circ} \mathrm{C}$ & $7 \mathrm{~min}$ \\
\hline
\end{tabular}

\section{Instruments}

5.1. Kiddie Schedule for Affective Disorders and SchizophreniaPresent and Lifetime Version (K-SADS-PL). This is a semistructured diagnostic interview, designed based on criteria defined by the Diagnostic and Statistical Manual for Mental Disorders, 4th edition (DSM-IV). This tool was to identify ADHD and possible comorbid psychiatric conditions as well as choosing controls [22].

The diagnostic procedure was completed through interview with child and the parents. The test-retest and interrater reliability of the Persian version is reported to be 0.81 and 0.69 [22].

5.2. PCR-Variable Number of Tandem Repeats. In his process, $2 \mathrm{~mL}$ peripheral blood samples were prepared and genomic DNA was extracted from it, using QIAamp DNA kit according to the manufacturer's instruction. The extracted DNA was quality-checked by using a NanoDrop device within the range of 260-280 $\mathrm{nm}$. The genotyping of DRD4 exon III was carried out by polymerase chain reaction with the following primer sequences:

\section{(Forward) $5^{\prime}$-GGTCTGCGGTGGAGTCTG-3' (Reverse) $5^{\prime}$-GCGACTACGTGGTCTACT-3'}

Amplification by PCR was performed in $20 \mu \mathrm{L}$ reaction mixture containing $50 \mathrm{ng}$ genomic DNA, using Ampliqon Master Mix (Denmark), $1 \mathrm{~mL}$ from each primer, and $0.2 \mu \mathrm{LTaq}$ DNA polymerase, according to temperature plan in Table 1. PCR products were observed in agar gel (2\%) stained with ethidium bromide fluorescence under ultraviolet light. Digestion products were analyzed after agarose gel electrophoresis.

\section{Statistical Analysis}

Data from counting the gene products in each sample was fed to SPSS21. Data are expressed as number and percentage, and the obtained mean values are investigated, using the Chisquare test. In this study, $p<0.05$ was considered significant.

\section{Results}

One hundred and thirty children diagnosed with ADHD and 130 children with no psychiatric diagnosis were enrolled. Mean age of children in the two groups was not significantly different. However, there were more males in the ADHD group ( $83 \%$ in the $\mathrm{ADHD}$ versus $61 \%$ control group). The role of a first-degree family relationship was present in many 
TABLE 2: Demographics of the study sample.

\begin{tabular}{lccc}
\hline Index & ADHD $(n=130)$ & Control $(n=130)$ & $p$ value \\
\hline Age (year) & $6.883 \pm 2.27$ & $6.98 \pm 2.50$ & 0.3 \\
Gender (boy/girl) & $108 / 22$ & $84 / 46$ & 61 \\
Percentage of ADHD boys & 83 & 4 & 0.001 \\
Children of first-degree family marriage (\%) & 56 & 4 & $<0.001$ \\
\hline
\end{tabular}

TABLE 3: Frequency of variable number of tandem repeats (VNTR) in exon 3 of the DRD4 gene in Iranian children.

\begin{tabular}{|c|c|c|c|c|c|}
\hline \multirow{2}{*}{ Number of repeats } & \multicolumn{2}{|c|}{ ADHD group } & \multicolumn{2}{|c|}{ Control group } & \multirow{2}{*}{$p$ value } \\
\hline & Number & Percentage & Number & Percentage & \\
\hline $2 \mathrm{R}$ & 3 & 2.3 & 9 & 6.9 & $>0.05$ \\
\hline $3 \mathrm{R}$ & 4 & 3.1 & 16 & 12.3 & $>0.05$ \\
\hline $4 \mathrm{R}$ & 99 & 76.2 & 70 & 53.8 & 0.004 \\
\hline $5 \mathrm{R}$ & 9 & 6.9 & 12 & 9.2 & $>0.05$ \\
\hline $6 \mathrm{R}$ & 8 & 6.2 & 11 & 8.5 & $>0.05$ \\
\hline $7 \mathrm{R}$ & 7 & 5.4 & 12 & 9.2 & $>0.05$ \\
\hline
\end{tabular}

samples. Descendants of a cousin marriage accounted for the majority of children with ADHD (Table 2). As the results show, the parents of ADHD children had a significantly higher proportion of first-degree relatives. Perhaps its cause is that there was a different pattern than the multifactorial pattern for this disorder. The study of pedigrees shows singlegene inheritance pattern; that is why the frequency of children with consanguineous marriage (especially the first cousins) was more than the control group.

Table 3 shows the frequency of VNTR DRD4 in the $\mathrm{ADHD}$ and control groups. The Hardy-Weinberg principle and Chi-square test showed a significant difference in $4 \mathrm{R}$ alleles between the ADHD (76.2\%) and control (53.8\%) groups $\left(p=0.004 ; X^{2}=17.39 ; \mathrm{df}=5\right)$. There was no significant between-groups difference in other repetitions. The $2 \mathrm{R}$ genotype had the lowest prevalence.

\section{Discussion}

$\mathrm{ADHD}$ is a prevalent neurobehavioral disorder starting during childhood [23]. According to several meta-analysis studies, genes involved in dopaminergic pathway, specifically DRD4, have an important role in pathogenesis of ADHD [1618]. There is no available study on the relationship of this topic in Iranian population and this study was conducted to use repetitions of this gene as a biomarker for facilitating the diagnosis of this disorder in children.

In the present study, the DRD4 gene was observed in all Iranian participants (ADHD and controls) within the range of $2 \mathrm{R}$ to $7 \mathrm{R}$ alleles. The dominant alleles in our study were $4 R, 5 R$, and $6 R$, among which the $4 R$ allele had the highest prevalence. The between-groups difference was significant only in $4 \mathrm{R}$ allele. Results of the present study are consistent with those of Bidwell et al. [19]. Cheuk et al. showed that the $4 \mathrm{R}$ allele had the highest frequency (84\%) among their research population; in addition, this genotype was correlated with presence of ADHD [24].
Though these studies were in line with the present study considering $4 \mathrm{R}$ as an indicator of $\mathrm{ADHD}$, studies on other populations, specifically White Europeans and Americans showed a greater role of $7 \mathrm{R}$ alleles in the development of ADHD [25]. In contrast, our study did not show any significant relationship between $7 \mathrm{R}$ alleles and ADHD.

Another meta-analysis study showed a significant difference in the relationship of ADHD and DRD4 7R in people of European-Caucasian and South American descent versus people of Middle Eastern Populations [26]. Leung et al. reported a very low prevalence of $7 \mathrm{R}$ alleles among Asians, whereas $4 \mathrm{R}$ had higher prevalence among them [27]. This report is consistent with the findings of our study.

According to demographic and ethnicity studies, it can be concluded that phylogenetics can be studied by investigating the polymorphism of genes in specific diseases. As it is seen, $4 \mathrm{R}$ is more prevalent in Asians than White Caucasians and Europeans [14]. High prevalence of $4 \mathrm{R}$ reported by Shahin et al. in Egypt [25], as well as our study confirms this finding.

However, there are studies that refuse the relationship of $7 \mathrm{R}$ alleles with ADHD. Carrasco et al. reports a negative relationship between 7R alleles and ADHD in a study conducted on a Chilean population [28]. Brookes et al. in a study in Taiwan reported no relationship between DRD4 biomarkers and ADHD [29].

The most obvious explanation for dissimilarity of reported results is differences of the study samples. However diagnostic procedure and methodological differences should also be accounted. The importance of a conclusion is not restricted to facilitating the diagnostic procedure but also might lead to preparing a precise treatment plan for each individual. Functional differences in the DRD4 intracellular signaling system have been studied for the 48-bp repeat alleles, and studies show that the 7R allele may be less sensitive to endogenous dopamine and mediates a blunted response to dopamine [12]. If results of the present study replicate in further studies, they might indicate good therapeutic 
response and better prognosis of ADHD in northwest of Iran.

It can be stated that the $4 \mathrm{R}$ allele carriers, which appear frequently in the ADHD patients in the northwest of Iran, may have a better prognosis than the carrier $7 \mathrm{R}$, which in other populations have been linked to ADHD. In other words, the $4 \mathrm{R}$ allele repeats in DRD4 gene can be considered as a prognostic diagnosis in ADHD disorder in this area of Iran.

\section{Conclusion}

In contrast to the results of studies conducted on White Europeans and Americans, in which 7R was the genetic indicator of ADHD, our study showed 4R as the variant of this disorder in northwest of Iran.

\section{Conflicts of Interest}

The authors declare that they have no conflicts of interest.

\section{Acknowledgments}

This study was supported by Research Center of Psychiatry and Behavioral Sciences, Tabriz University of Medical Sciences. The authors thank all participants of this study.

\section{References}

[1] G. A. Stefanatos and I. S. Baron, "Attention-deficit/hyperactivity disorder: a neuropsychological perspective towards DSM-V," Neuropsychology Review, vol. 17, no. 1, pp. 5-38, 2007.

[2] S. Amiri, A. Fakhari, M. Maheri, and A. Mohammadpoor Asl, "Attention deficit/hyperactivity disorder in primary school children of Tabriz, North-West Iran," Paediatric and Perinatal Epidemiology, vol. 24, no. 6, pp. 597-601, 2010.

[3] R. A. Barkley, Attention-Deficit Hyperactivity Disorder: A Handbook for Diagnosis and Treatment, Guilford Publications, 2014.

[4] J. Biederman, A. F. Arnsten, S. V. Faraone, A. E. Doyle, T. J. Spencer, T. E. Wilens et al., "New developments in the treatment of ADHD," Journal of Clinical Psychiatry, vol. 67, no. 01, pp. 148159, 2006.

[5] D. Wallis, H. F. Russell, and M. Muenke, "Review: genetics of attention deficit/hyperactivity disorder," Journal of Pediatric Psychology, vol. 33, no. 10, pp. 1085-1099, 2008.

[6] L. Culpepper and G. Mattingly, "Challenges in identifying and managing attention-deficit/hyperactivity disorder in adults in the primary care setting: a review of the literature," Primary Care Companion to the Journal of Clinical Psychiatry, vol. 12, no. 6, 2010.

[7] A. M. Hamed, A. J. Kauer, and H. E. Stevens, "Why the diagnosis of attention deficit hyperactivity disorder matters," Frontiers in Psychiatry, vol. 6, article 168, 2015.

[8] A. M. Reiersen and A. A. Todorov, "Association between DRD4 genotype and autistic symptoms in DSM-IV ADHD," Journal of the Canadian Academy of Child and Adolescent Psychiatry, vol. 20, no. 1, pp. 15-21, 2011.

[9] S. B. Floresco and M. T. Tse, "Dopaminergic regulation of inhibitory and excitatory transmission in the basolateral amygdalaprefrontal cortical pathway," Journal of Neuroscience, vol. 27, no. 8, pp. 2045-2057, 2007.
[10] D. Noaín, M. E. Avale, C. Wedemeyer, D. Calvo, M. Peper, and M. Rubinstein, "Identification of brain neurons expressing the dopamine D4 receptor gene using BAC transgenic mice," European Journal of Neuroscience, vol. 24, no. 9, pp. 2429-2438, 2006.

[11] J. Gelernter, J. L. Kennedy, H. H. M. van Tol, O. Civelli, and K. K. Kidd, "The D4 dopamine receptor (DRD4) maps to distal 11p close to HRAS," Genomics, vol. 13, no. 1, pp. 208-210, 1992.

[12] J. N. Oak, J. Oldenhof, and H. H. M. Van Tol, "The dopamine D4 receptor: one decade of research," European Journal of Pharmacology, vol. 405, no. 1-3, pp. 303-327, 2000.

[13] J. Wu, H. Xiao, H. Sun, L. Zou, and L.-Q. Zhu, "Role of dopamine receptors in ADHD: a systematic meta-analysis," Molecular Neurobiology, vol. 45, no. 3, pp. 605-620, 2012.

[14] Z. Hawi, M. McCarron, A. Kirley, G. Daly, M. Fitzgerald, and M. Gill, "No association of the dopamine DRD4 receptor (DRD4) gene polymorphism with attention deficit hyperactivity disorder (ADHD) in the Irish population," American Journal of Medical Genetics - Neuropsychiatric Genetics, vol. 96, no. 3, pp. 268-272, 2000.

[15] H. H. Tol, C. M. Wu, H. Guan et al., "Multiple dopamine D4 receptor variants in the human population," Nature, vol. 358, no. 6382, pp. 149-152, 1992.

[16] I. R. Gizer, C. Ficks, and I. D. Waldman, "Candidate gene studies of ADHD: a meta-analytic review," Human Genetics, vol. 126, no. 1, pp. 51-90, 2009.

[17] D. Li, P. C. Sham, M. J. Owen, and L. He, "Meta-analysis shows significant association between dopamine system genes and attention deficit hyperactivity disorder (ADHD)," Human Molecular Genetics, vol. 15, no. 14, pp. 2276-2284, 2006.

[18] A. Nikolaidis and J. R. Gray, "ADHD and the DRD4 exon III 7repeat polymorphism: An international meta-analysis," Social Cognitive and Affective Neuroscience, vol. 5, no. 2-3, Article ID nsp049, pp. 188-193, 2009.

[19] L. C. Bidwell, E. G. Willcutt, M. B. McQueen et al., "A family based association study of DRD4, DAT1, and 5HTT and continuous traits of attention-deficit hyperactivity disorder," Behavior Genetics, vol. 41, no. 1, pp. 165-174, 2011.

[20] C. Marino, R. Giorda, L. Vanzin et al., "No evidence for association and linkage disequilibrium between dyslexia and markers of four dopamine-related genes," European Child and Adolescent Psychiatry, vol. 12, no. 4, pp. 198-202, 2003.

[21] S. Johansson, H. Halleland, A. Halmøy et al., "Genetic analyses of dopamine related genes in adult ADHD patients suggest an association with the DRD5-microsatellite repeat, but not with DRD4 or SLC6A3 VNTRs," American Journal of Medical Genetics, Part B: Neuropsychiatric Genetics, vol. 147, no. 8, pp. 1470-1475, 2008

[22] A. Ghanizadeh, M. R. Mohammadi, and A. Yazdanshenas, "Psychometric properties of the Farsi translation of the kiddie schedule for affective disorders and schizophrenia-present and lifetime version," BMC Psychiatry, vol. 6, article 10, 2006.

[23] Subcommittee on Attention-Deficit/Hyperactivity Disorder and Steering Committee on Quality Improvement and Management, "ADHD: clinical practice guideline for the diagnosis, evaluation, and treatment of attention-deficit/ hyperactivity disorder in children and adolescents," Pediatrics, vol. 128, no. 5, pp. 1007-1022, 2011.

[24] D. K. L. Cheuk, S. Y. H. Li, and V. Wong, "Exon 3 polymorphisms of dopamine D4 receptor (DRD4) gene and attention deficit hyperactivity disorder in Chinese children," American 
Journal of Medical Genetics, Part B: Neuropsychiatric Genetics, vol. 141, no. 8, pp. 907-911, 2006.

[25] O. Shahin, N. A. Meguid, O. Raafat, R. M. Dawood, M. Doss, and N. G. Bader El Din, "Polymorphism in variable number of tandem repeats of dopamine D4 gene is a genetic risk factor in attention deficit hyperactive egyptian children: pilot study," Biomarker Insights, vol. 10, pp. 33-38, 2015.

[26] A. Nikolaidis and J. R. Gray, "ADHD and the DRD4 exon III 7-repeat polymorphism: an international meta-analysis," Social Cognitive and Affective Neuroscience, vol. 5, no. 2-3, Article ID nsp049, pp. 188-193, 2009.

[27] P. W. L. Leung, C. C. Lee, S. F. Hung et al., "Dopamine receptor D4 (DRD4) gene in Han Chinese children with AttentionDeficit/Hyperactivity Disorder (ADHD): increased prevalence of the 2-repeat allele," American Journal of Medical Genetics Neuropsychiatric Genetics, vol. 133, no. 1, pp. 54-56, 2005.

[28] X. Carrasco, P. Rothhammer, M. Moraga et al., "Genotypic interaction between DRD4 and DAT1 loci is a high risk factor for attention-deficit/hyperactivity disorder in Chilean families," American Journal of Medical Genetics - Neuropsychiatric Genetics, vol. 141, no. 1, pp. 51-54, 2006.

[29] K.-J. Brookes, X. Xu, C.-K. Chen, Y.-S. Huang, Y.-Y. Wu, and P. Asherson, "No evidence for the association of DRD4 with ADHD in a Taiwanese population within-family study," $B M C$ Medical Genetics, vol. 6, article 31, 2005. 

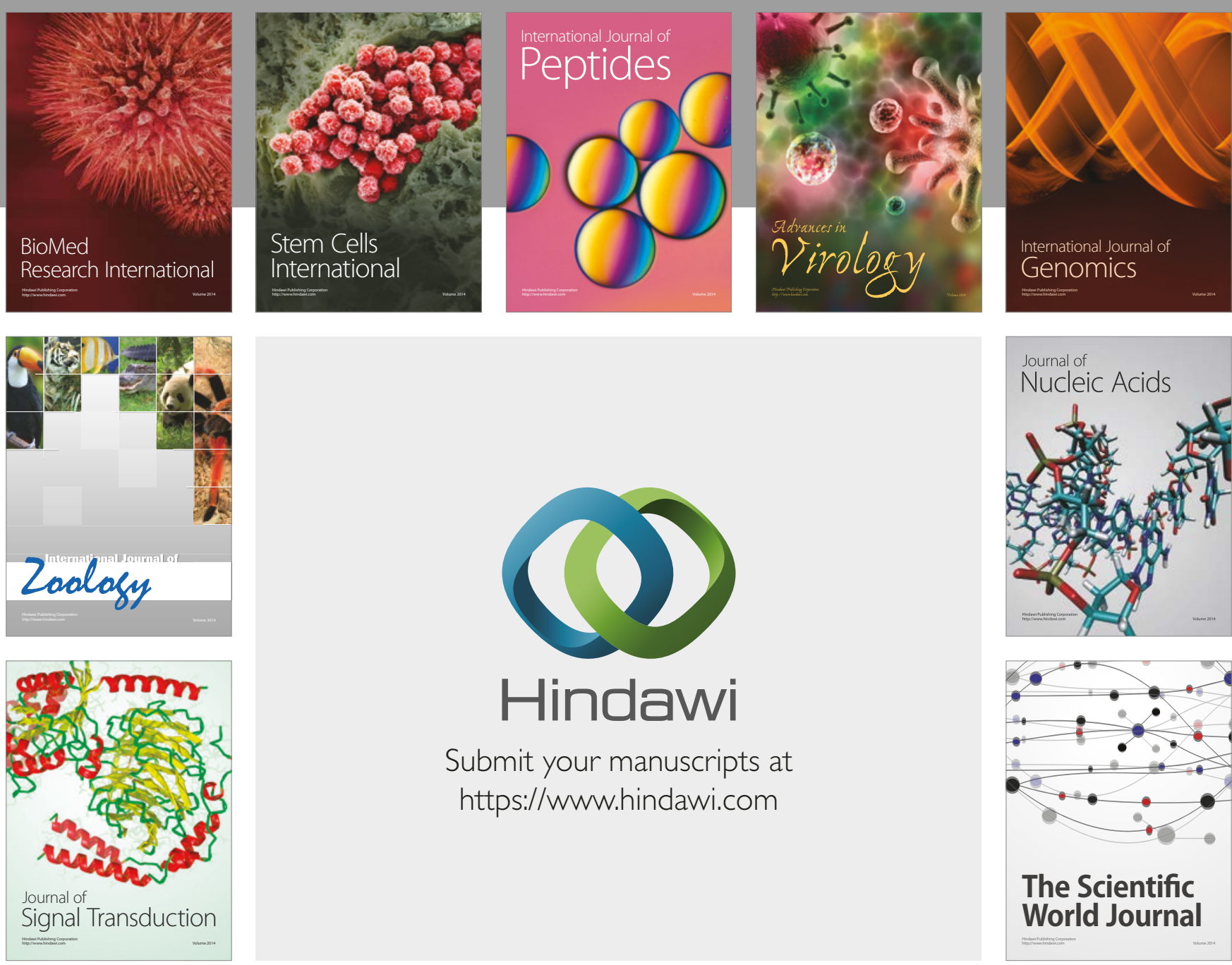

Submit your manuscripts at

https://www.hindawi.com
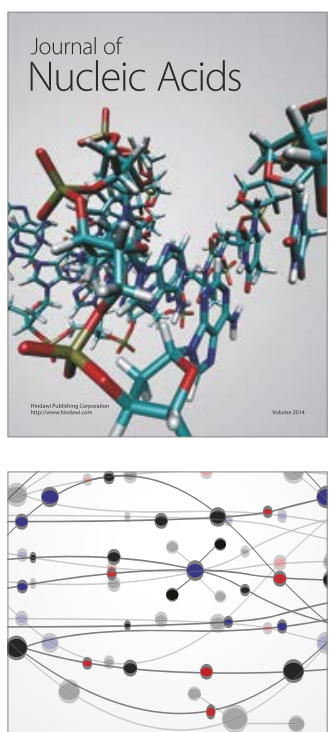

The Scientific World Journal

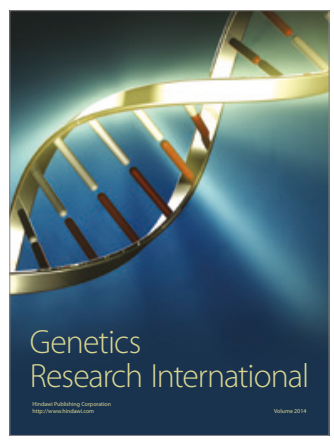

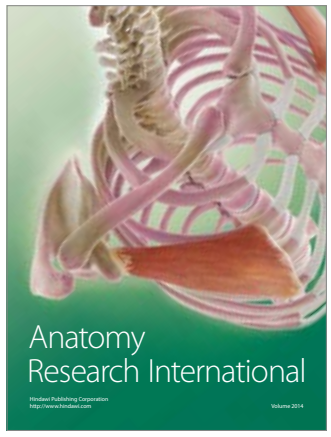

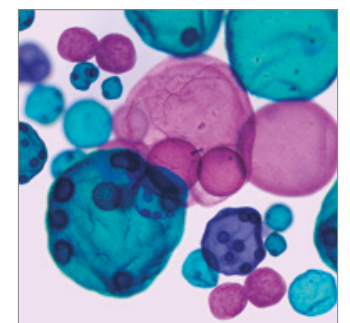

International Journal of Microbiology
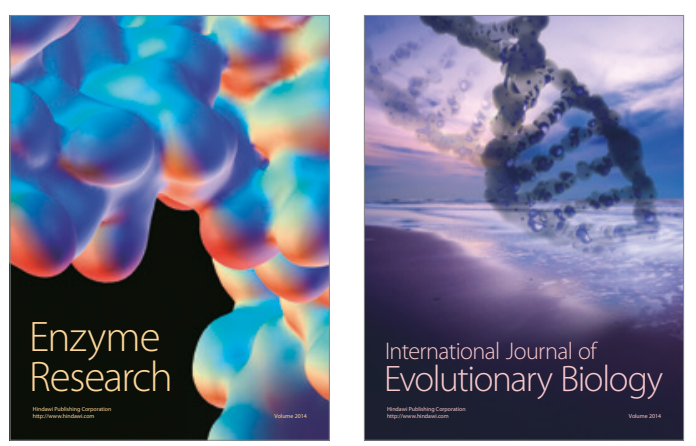
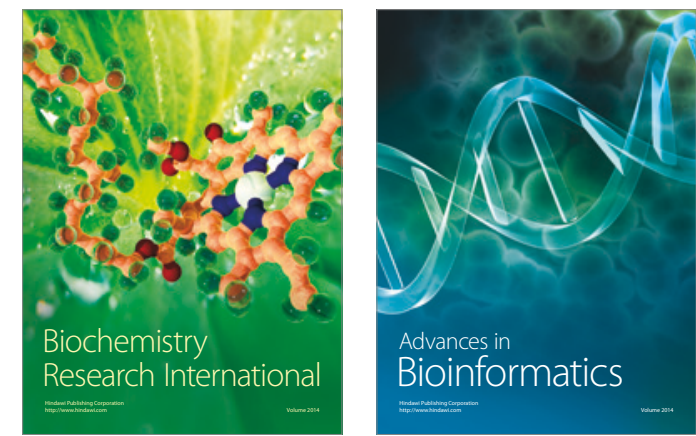

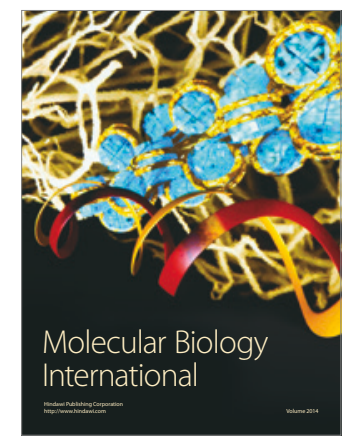

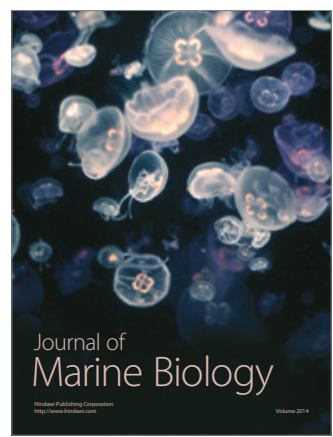

